\title{
A clinical study to evaluate the outcome of diaphyseal humerus fracture in adult age group treated with anterior biological plating
}

\author{
Vala G. ${ }^{1}$, Mahendrabhai Patel J. ${ }^{*}$, Vora J. ${ }^{3}$ \\ DOI: https://doi.org/10.17511/ijoso.2020.i02.06
}

\footnotetext{
${ }^{1}$ Gaurav Vala, Associate Professor, Department of Orthopaedics, C.U. Shah Medical College, Surendranagar, Gujarat, India.

2* Jay Mahendrabhai Patel, Resident Doctor, Department of Orthopaedics, C.U. Shah Medical College, Surendranagar, Gujarat, India. https://orcid.org/0000-0003-1453-1649

3 Jinesh Vora, Associate Professor, Department of Orthopaedics, C.U. Shah Medical College, Surendranagar, Gujarat, India.
}

Background: Anterior biological plating is one of the many options to treat diaphyseal humerus fractures in the adult age group. A clinical study was performed to evaluate outcomes over 6 months follow up period in 25 patients. Materials and Methods: The present study included 25 patients of the adult age group having diaphyseal humerus fracture treated with anterior biological plating between February 2018 to June 2019.Pathological, Malunited, and Gustilo Anderson open to grade 3 fractures were excluded from the study. Locking Compression Plating was done in all cases using the MIPO technique after closed indirect reduction. Functional outcome was assessedusing the DASH score at 6 months follow up. Results: The study consisted of 16 males and 9 females. The mean age was 42.36 years (range: $19-73$ years). 7 fractures out of 25 were $12 \mathrm{~A} 1$, 2 were $12 \mathrm{~A} 2,10$ were $12 \mathrm{~A} 3,2$ were $12 \mathrm{~B} 1$ and 4 were $12 \mathrm{~B} 2$ based on $\mathrm{AO}$ classification. Mean DASH score in the present study was 7.9 with 21 patients achieving excellent DASH Score and 4 patients achieving good DASH score with none of the patients having fair or poor DASH scores. Conclusion: ABP for mid-shaft humerus fractures is a safe and effective treatment modality yielding high rates of the union, excellent functional recovery, minimal biological disruption, better cosmesis, and superior patient satisfaction.

Keywords: Anterior biological plating (ABP), Minimal invasive plate osteosynthesis (MIPO), Diaphyseal humerus fractures, Shaft humerus fractures

Corresponding Author

Jay Mahendrabhai Patel, Resident Doctor,
Department of Orthopaedics, C.U. Shah Medical
College, Surendranagar, Gujarat, India.
Email: jaypatel.apps_@gmail.com

\section{How to Cite this Article}

Vala G, Patel JM, Vora J. A clinical study to evaluate the outcome of diaphyseal humerus fracture in adult age group treated with anterior biological plating. Surgical Review Int J Surg Trauma Orthoped. 2020;6(2):99-104.

Available From

https://surgical.medresearch.in/index.php/ijoso/artic le/view/157
To Browse

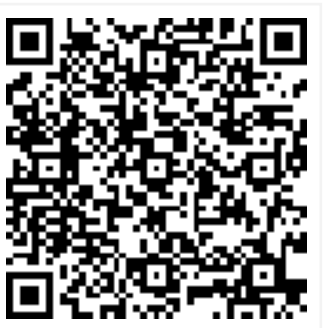

Manuscript Received 10-03-2020

Conflict of Interest No
Review Round 1 20-03-2020

Funding

Nil

Review Round 2
26-03-2020
Ethical Approval
Yes

Review Round 2

Yes
Review Round 3

Plagiarism X-checker $12 \%$
Accepted 02-04-2020

Note

2020 by Gaurav Vala, Jay Mahendrabhai Patel, Jinesh Vora and Published by Siddharth Health Research and Social Welfare Society. This is an Open Access article licensed under a Creative Commons Attribution 4.0 International License https://creativecommons.org/licenses/by/4.0/ unported [CC BY 4.0]. 


\section{Introduction}

Humeral shaft fractures account for 1 to $3 \%$ of all fractures in adults [1-3] and for $20 \%$ of all humeral fractures[4]. These fractures have an annual incidence from 13 to 14.5 per 100,000 people $[5,6]$. The humerus can be considered the most versatile bone in the human body in view of the fact that it can be successfully approached by a variety of methods for fracture fixation including functional bracing, plating (posterior, lateral, and anterior), and intramedullary nailing (antegrade and retrograde). Humeral shaft fracture frequently requires operative fixation. However, there remains controversy concerning the ideal method of fixation. The traditional open posterior plating is a rotator cuff safe technique; however, biological disruption of soft tissue, poor cosmetic scarring, and direct handling of the radial nerve have been of concern. On the other hand, the classical intramedullary nailing is minimally invasive, but it has the main drawback of potentially damaging the rotator cuff and causing shoulder impingement. The ABP is designed to combine the best features of these two techniques: therefore, it is minimally invasive and cosmetic friendly and causes minimal manipulation of vital structures. A clinical study was performed to evaluate the outcome of diaphyseal humerus fracture treated with anterior biological plating in the adult age group at $\mathrm{C} \cup$ Shah Medical College between February 2018 to June 2019 in a prospective study.25 patients were selected randomly. The inclusion criteria were fit and well patients who had agreed for informed written consent and belonged to the adult age group with closed or open grade 1 or 2 diaphyseal fractures of the humerus. The current study excluded patients with open grade 3 fractures, pathological fractures, fractures of more than 3 weeks duration, and fractures near the joints from the present study. Data were collected by a set of questionnaires and assessment was done using the DASH score. Patients were followed up for 6 months.

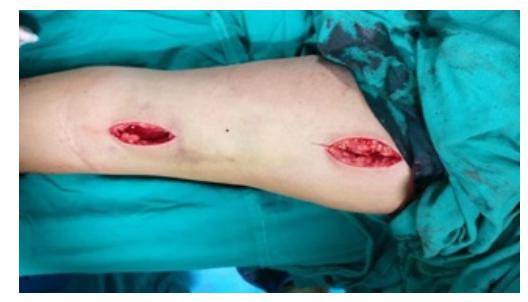

Fig-1: Under general anesthesia or supraclavicular block, the procedure was performed with two incisions, one $3-\mathrm{cm}$
Incision in the proximal part and another $3-\mathrm{cm}$ incision in the distal part of the standard anterior approach to the humerus [8].

The fractures were classified according to the AO method [7]. The current study fixed the fractures with a narrow long 4.5-mm locking compression plate. Closed reduction and fixation were achieved under the C-arm image with the machine on the same side as the arm being operated and avoiding manipulation of the arm during the procedure while maintaining elbow in 70-degree flexion and supination after achieving the manual reduction of the fracture. The submuscular tunnel was created by finger dissection and using the edge of the plate, under the brachialis muscle extraperiosteally. Temporary fixation of the appropriate plate was done with $2 \mathrm{~mm}$ K-wires and the position confirmed under image intensifier before definitive fixation. Long narrow LCP was fixed anteriorly across the fracture with 2 or 3 screws on either side. The rotational deformity was avoided by noting the 'cortical step sign' and the 'diameter difference sign' as described by Krettek [9]. The current study followed the standard and defined protocol for the study after getting hospital ethical committee clearance. Informed written consent was taken from patients. Patients were evaluated clinically noting the function of the radial nerve, the condition of the skin and soft tissues, preoperatively. Anteroposterior and lateral radiographs were used to template the exact length of the implant and preoperative planning of the fixation of the fracture with screws.

Postoperative care- Postoperative patients were immobilized with humerus brace. Intravenous antibiotics are given for 2 to 3 days then shifted to oral antibiotics. Shoulder and elbow mobilization was started from 1st postoperative day. Suture removal was done on 10 th-12th postoperative day Patients were called for follow up at a duration of 1 month and clinically status and fracture union noted. X-rays were taken to confirm the progress of the union. The shoulder and elbow range of motion was noted. Any complaints regarding pain are noted. Any improvement in post-traumatic radial nerve palsy noted.

Patients were regularly followed up at regular intervals till fracture was completely united. All patients were advised for regular physiotherapy for improvement of shoulder and elbow movements. Patients were evaluated with DASH Score at 6 months follow up. At least 27 of the 30 items must 
Be completed for a score to be calculated. DASH disability/symptom score $=[$ (sum of $n$ responses) 1] $x 25$ where $n$ is equal to the number of completed responses.

\section{Results}

The study consisted of 16 males and 9 females. The mean age was 42.36 years(range: $19-73$ years).7 fractures out of 25 were $12 \mathrm{~A} 1,2$ were $12 \mathrm{~A} 2,10$ were $12 \mathrm{~A} 3,2$ were $12 \mathrm{~B} 1$ and 4 were $12 \mathrm{~B} 2$ based on $\mathrm{AO}$ classification. Road traffic accidentswere the most common mode of injury involving 15 cases, 6 were due to slip and fall and 4 of them occurred after the assault. Out of 25 pts, only one fracture was open grade 1 , the other 24 were closed. No patient had preoperative radial nerve palsy.4 patients had associated injuries of which 1 patient had a fracture in the same extremity. Postoperative injectable antibiotics were given for an average duration of 3.3 days. Suture removal was done on postoperative day 11.26 on average. Postoperative immobilization was given for an average of 1.26 months. Out of 25 pts in the study 4 pt developed postoperative radial nerve palsy which resolved without any surgical interventions in the mean duration of 6.2 weeks. None of the patients in the study developed an infection. Non-union, implant failure, or periprosthetic fracture. Mean DASH score in the present study was 7.9 with 21 patients achieving an excellent DASH Score and 4 patients achieving a good DASH score with none of the patients having fair or poor DASH scores.
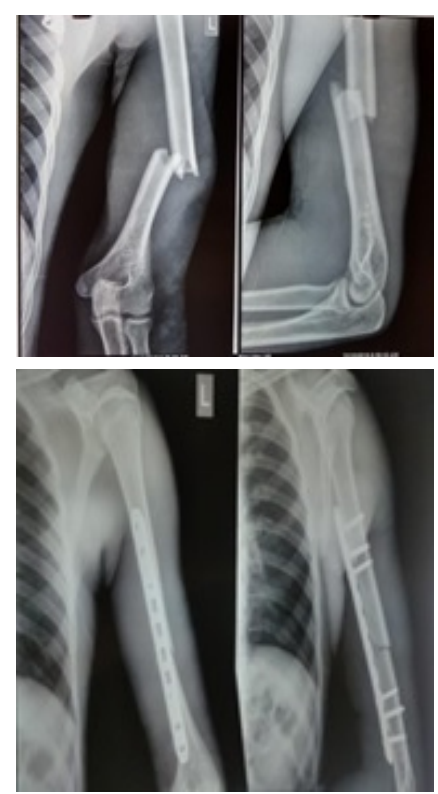

Fig-2: Preoperative x-ray.Fig-3: Immediate postoperative $x$-ray.

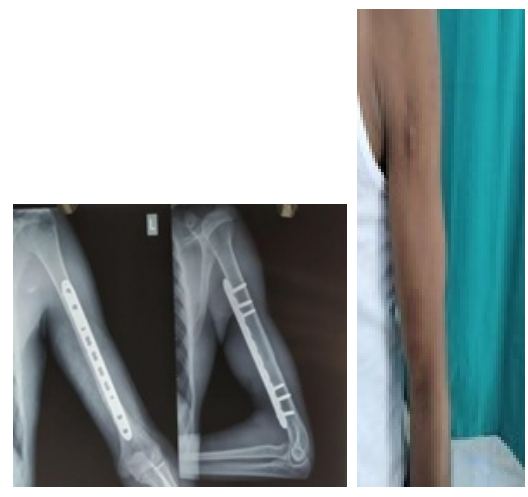

Fig-4: 6 months follow up x-ray.Fig-5: Scar at 6 months.
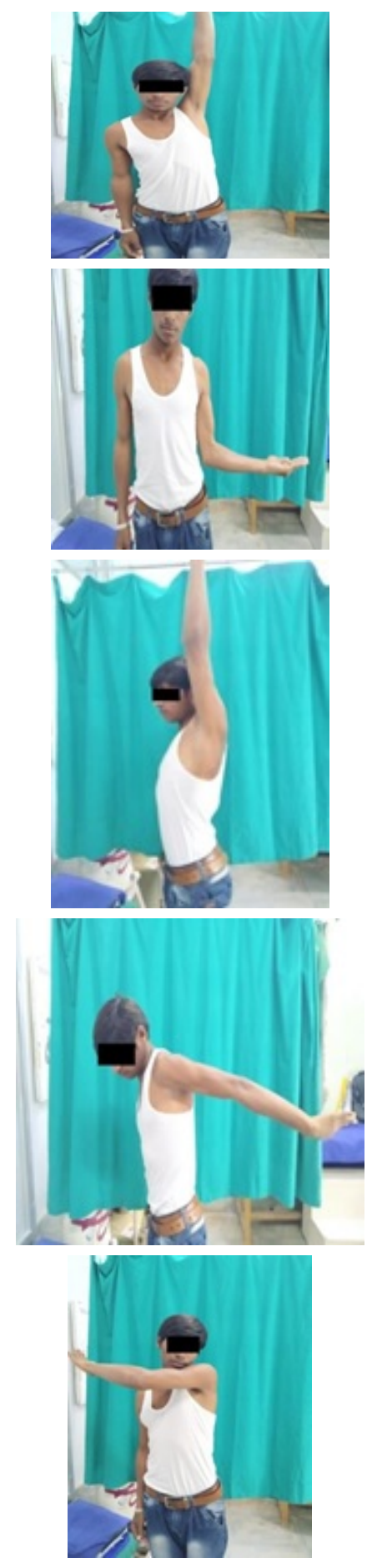

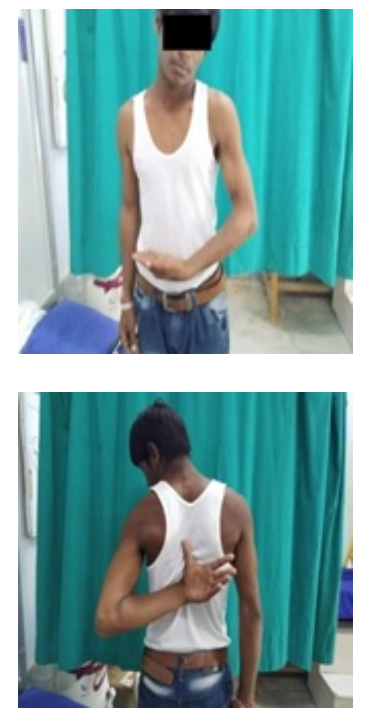

Fig-6: Range of motion at 6 months.

\section{Discussion}

As described by Sarmiento et al [10] the humerus bone has a wide range of acceptability criteria in its reduction and is highly amenable to conservative management. However, it requires the continuous use of a cast/splint for 6-8 weeks, which is usually cumbersome for the patient. This option is not very suitable in the modern era where patients want to begin their activities at the earliest. So, these patients are better suited for early operative intervention. The minimally invasive technique for fracture treatment has evolved based on the idea that with the preservation of fracture hematoma and the vascularity around the fracture site, new bone is laid down in the form of callus, a fact which was recognized by Albrecht Haller's (1708-1777) [11] and led to the success of the MIPO technique for fracture fixation at other sites and lies in the fact that using long plates across zones of extensive fracture fragmentation with only a few screws on either side of the fracture which withstands considerable deforming forces, though the tension side for the shaft of the humerus and the expected placement of the plate lies posteriorly where the plate should be placed, according to principles. The idea has evolved from the knowledge of the fact that with minimal stress per unit area, the bending stress gets distributed over a long segment of the plate with the resultant reduced risk of plate failure [11] allowing successful fixation as the construct becomes elastic $[12,13]$. The disadvantage of extensive soft tissue dissection required for ORIF has promoted the development of a less invasive technique that allows indirect reduction and percutaneous plating of the anterior humerus and
Has been reported to, using the above knowledge. Earlier reports have shown excellent healing rates and alignment, and rare incidences of complications. Humeral shaft fractures constitute around $3-5 \%$ of all fractures [14]. MIPPO is technically demanding and needs intraoperative imaging in order to obtain adequate fracture alignment. Scarring of brachialis muscle and inadequate postoperative rehabilitation, contribute to limited elbow range of motion. Long plates used to bridge an extensive zone of fragmentation with the only short fixation on either end of the bone can achieve union at the fracture site by callus formation provided the fracture hematoma is undisturbed. This process is augmented by micromotion at the fracture site. The primary advantage of $A B P$ is the combination of stability with minimal soft tissue and periosteal disruption. Unlike the posterior plating option, it requires a small incision and adheres to the MIPPO principle, which is biologically and cosmetically preferable. It maintains the periosteal circulation contrary to the method of application of the plate on the bone by an open technique that interferes with the local vascularization, leading to the possible osteonecrosis beneath the implant, ending up in delayed healing or non-union. The disadvantage of primary bone healing without callus formation is the risk of refracture after removal of the implant following an open technique. In addition, the rotator cuff is spared preventing any major shoulder pathology later on, which is the case in humeral nailing. An important thing is to keep in mind the course of the radial nerve near the distal end of the plate, which usually lies a few centimeters distal to the point where the nerve pierces the lateral intermuscular septum. Sliding of the plate in a wrong fashion, careless drilling for the distal screws or overzealous retraction can lead to neuropraxia. The brachialis muscle covers the humerus anteriorly and protects the radial nerve from injury when a plate is inserted submuscularly. Apivatthakakul et al. [15] have described the danger zone for the radial nerve with respect to percutaneous locking screw placement which lies $36.35 \%-59.2 \%$ of the humeral length predominantly in the middle third of the humeral shaft and that for the musculocutaneous nerve lies, on an average, $18.37 \%-42.67 \%$ of the humeral length from the lateral epicondyle [15]. With due care and the note of these tips the complications which may be encountered from faulty technique could be minimized. The radial nerve follows a fixed course, anatomically [15] According to Apivatthakakul et al. $\lceil 15\rceil$ "when a plate is placed on the anterior side of 
The humeral shaft, the mean distance from the closest part of the plate to the radial nerve is 3.2 $\mathrm{mm}$. and on pronation of the forearm, the radial nerve was noted to move medially closer to the distal end of the plate and was at risk of iatrogenic injury?. For this reason, the supination position of the forearm should be maintained during the entire procedure. The study of postoperative ultrasonographic measurement of the distance between the radial nerve and the implant used in the MIPPO technique by Livani et al. substantiates this fact [16]. The present study included 25 adult patients operated for diaphyseal humeral fractures treated with anterior biological platting the result of which is compared to other studies as follows. In the present study none of the patients developed the infection, 4 patients (16\%) developed radial nerve palsy, none of the patients developed nonunion or implant failure. All patients who developed postoperative radial nerve palsy recovered without any surgical interventions in the mean duration of 6.2 weeks. Our result compared to the other studies is as follows

\begin{tabular}{|l|l|l|l|}
\hline \multicolumn{1}{|c|}{ Complications } & \multicolumn{1}{|c|}{$\begin{array}{c}\text { Zogaibet } \\
\text { al[17] }\end{array}$} & $\begin{array}{c}\text { Mahajanet } \\
\text { al[18] }\end{array}$ & Present study \\
\hline Infection (\%) & 0 & 0 & 0 \\
\hline $\begin{array}{l}\text { Radial nerve palsy } \\
(\%)\end{array}$ & 0 & 0 & 16 \\
\hline Non-union (\%) & 0 & 4.17 & 0 \\
\hline Implant failure (\%) & 8.69 & 0 & 0 \\
\hline
\end{tabular}

In the present study, the functional assessment was done using the DASH Score.The mean DASH score was 7.9 which is compared to other studies.

\begin{tabular}{|l|l|l|l|}
\hline & Zogaiibet al[17] & Mahajanet al[18] & Present study \\
\hline Mean DASH Score & 5.45 & 4.71 & 7.9 \\
\hline
\end{tabular}

All of the patients were treated using 4.5 Narrow LCP. Cortical screws were used if the only alignment of the shaft with plate was unsatisfactory. Two or three locking screws were used in proximal and distal fragments. The need for additional reduction techniques was not needed except for two patients in which antegrade fibula rush pin was used for better alignment of the shaft. All of the patients developed a union without any screw loosening or implant failure in the present study. Mean DASH score in the present study was 7.9 which is comparable to other published studies with 21 patients achieving excellent DASH Score and 4 patients achieving good DASH score with none of the patients having fair or poor DASH score. The most common difficulties observed were carrying a heavy object (over $10 \mathrm{lbs}$.) and washing their back.
The most common complaint was pain over the fracture site which persisted for an average of 2 months. The only complication in the presentstudy (in 4 patients) was the development of postoperative radial palsy which recovered without any surgical intervention in the mean duration of 6.2 weeks. The high rate of radial nerve palsy in the present study may be attributed to the learning curve as the technique of anterior biological plating for fracture diaphyseal humerus is relatively new at our institute. None of the patients in the present study have developed infection, nonunion, or implant failure.Limitations to the present study were the lack of a comparison group of patients of diaphyseal fractures treated with other modalities which could have provided us with information aboutthe advantages and disadvantages of MIPO technique over others.

\section{Conclusion}

In conclusion, $\mathrm{ABP}$ for mid-shaft humerus fractures is a safe and effective treatment modality yielding high rates of the union, excellent functional recovery, minimal biological disruption, better cosmesis, and superior patient satisfaction.

\section{What does the study add to the existing knowledge?}

Although there are many studies regarding the various management modalities for diaphyseal humeral shaft fracture which includes both conservative and operative management, there are only a few good studies that include minimally invasive plate osteosynthesis technique. The aim of our study was to study this relatively new technique of operative management, observe the results and compare them to already published studies on this technique.

\section{Author's contribution}

Dr. Gaurav Vala: Study design and concept. Dr. Jay Patel:Collection of data, compilation, statistical analysis, and preparing the manuscript. Dr. Jinesh Vora: Preparation of the manuscript.

\section{Reference}

01. Hoppenfeld S, de Boer P. Surgical Exposures in Orthopedics. Philadelphia, PA- JB, Lippincott. 1984.

[Crossref] 
02. Emmett JE, Breck LW. A review and analysis of 11,000 fractures seen in a private practice of orthopaedic surgery, 1937-1956. J Bone Joint Surg Am. 1958;40-A(5)1169-1175.

[Crossref]

03. Gustilo RB, Anderson JT. Prevention of infection in the treatment of one thousand and twentyfive open fractures of long bones- retrospective and prospective analyses. J Bone Joint Surg Am. $1976 ; 58(4) 453-458$.

[Crossref]

04. Schemitsch EH, Bhandari M, Talbot M. Fractures of the humeral shaft, In Skeletal Trauma- Basic Science, Management and Reconstruction. Philadelphia- Saunders. volume 2, 4th edition, 2008;1593-1594.

[Crossref]

05. Rose SH, Melton LJ 3rd, Morrey BF, Ilstrup DM, Riggs BL. Epidemiologic features of humeral fractures. Clin Orthop Relat Res. 1982,168;2430.

[Crossref]

06. Ekholm R, Adami J, Tidemark J, Hanson K, Törnkvist $H$, Ponser S. Fractures of the shaft of the humerus- an epidemiological study of 401 fractures. J Bone Joint Surg Br. 2006;88$B(11) 1469-1473$.

doi: 10.1302/0301-620x.88b11.17634[Crossref]

07. Fracture and Dislocation Classification Compendum. Humerus. J Orthop Trauma. 2018;32(1)S15-16.

doi:10.1097/BOT.0000000000001062[Crossref]

08. Krettek C, Schandelmaier P, Tscherne H. Distal femoral fractures- Transarticular reconstruction, percutaneous plate osteosynthesis and retrograde nailing [in German]. Unfallchirug. 1996; 99;2-1038.

[Crossref]

09. Apivatthakakul T, Arpornchayanon O, Bavornratanavech S. Minimally invasive plate osteosynthesis (MIPO) of the humeral shaft fracture- Is it possible? A cadaveric study and preliminary report. Injury. 2005;36(4)530-538. doi:10.1016/j.injury.2004.05.036[Crossref]

10. Wagner M, Frigg R. AO Manual of fracture management- Internal fixators. Chapters 12Concepts of fracture fixation. 2006. ¡Crossref]
11. Brinker MR, O'Connor DP. The incidence of fractures and dislocations referred for orthopaedic services in a capitated population. J Bone Joint Surg Am. 2004;86-A(2)290-297. [Crossref]

12. Sarmiento A, Zagorski JB, Zych GA, Latta LL, Capps CA. Functional bracing for the treatment of fractures of the humeral diaphysis. J Bone Joint Surg Am. 2000;82(4)478-486. doi:10.2106/00004623-200004000-00003[Crossref]

13. Baumgaertel $F$, Buhl $M$, Rahn BA. Fracture healing in biological plate osteosynthesis. Injury. 1998;29(3)C3-C6. doi:10.1016/s0020-1383(98)95002-1[Crossref]

14. Dickson KF, Munz JW. Locked platingBiomechanics Biology. Tech Orthop. 2007;22(4)E1-E6.

[Crossref]

15. Wagner M, Frenk A, Frigg R. Locked platingBiomechanics and biology and locked platingClinical indications. Tech Orthop. 2007;22;4. [Crossref]

16. Livani B, Belangero W, Andrade K, Zuiani G, Pratali R. Is MIPO in humeral shaft fractures really safe? Postoperative ultrasonographic evaluation. Int Orthop. 2009;33(6)1719-1723. doi: $10.1007 \% 2 F s 00264-008-0616-x$ [Crossref]

17. Zogaib RK, Morgan S, Belangero PS, Fernandes HJA, Belangero WD, Livani B. Minimal invasive osteosynthesis for treatment of diaphyseal transverse humeral shaft fractures. Acta Ortop Bras. 2014;22(2)94-98. doi:10.1590/1413-78522014220200698[Crossref]

18. MahajanAS, Kim YG, Kim JH,D'sa P, Lakhani A, Ok HS. Is Anterior Bridge Plating for Midshaft Humeral Fractures a Suitable Option for Patients Predominantly Involved in Overhead Activities? A Functional Outcome Study in Athletes and Manual Laborers. Clin Orthop Surg. $2016 ; 8(4) 358-366$. doi: $10.4055 /$ cios.2016.8.4.358[Crossref] 